\title{
SUGGESTIBILITY AND HYSTERIA
}

\begin{abstract}
Introduction
The present paper is concerned with two problems which, although they may with advantage be treated separately on the theoretical level, are closely connected. The first, or clinical problem, is concerned with the relationship obtaining between hysteria and suggestibility ; the second, or psychological problem, is concerned with the nature of suggestibility, and its relation to a number of other psychological variables, such as intelligence, perseveration, and personal tempo.
\end{abstract}

The clinical problem.-In his Major Symptons of Hysteria, Janet (1907, p. 292) set forth a view of the relation between suggestibility and hysteria which has had a profound influence on psychiatry. He maintained that "suggestion is a precise and relatively rare phenomenon; it presents itself experimentally or accidentally only with hystericals, and, inversely, all hystericals, when we study them from this standpoint, present this same phenomenon in a higher or lower degree. ... The most important mental stigma of hysteria is suggestibility." (Janet's italics). This view was echoed by Babinski and Froment (1918), who maintained that hysteria consists in manifestations which are brought into existence by the influence of suggestion, and that the essential feature of the hysterical personality is abnormal suggestibility. The adherents of the Nancy school, while maintaining that all men are suggestible under favourable conditions, agree with Janet and Babinski in maintaining that the hysterical patient differs from the normal human being chiefly in that his suggestibility is more or less increased, owing to the prevalence of a state of cerebral dissociation (Bernheim, 1887).

While this view regarding the special relationship between suggestibility and hysteria seems to have flourished especially in France, it is by no means restricted to that country. McDougall (1911) points out that "a high degree of 'Suggestibility' is a leading feature of hysteria "; Jacoby (1912) speaks of " the special relationship between suggestion and hysteria," quoting Morton Prince in support; Rosanoff (1920) quotes Babinski with approval, as does Noyes (1939). Shaffer (1936) speaking of the personality of hysterics, asserts that they tend to be more suggestible; Morgan (1936) lists suggestibility among the most characteristic features of hysteria ; Hirschlaff (1919), Tuckey (1921), Satow
BY

It had also been suggested, particularly by Stephenson (1934) and Cattell (1936), that a negative relation obtains between hysteria and perseveration ; consequently, two tests of perseveration were included in the battery. On a priori grounds it appeared possible that personal tempo might be correlated with hysteria, and accordingly this personal trait, too, was tested.

The psychological problem.-Before a trait such as suggestibility can be measured it is essential that it be proved a unitary trait. In other words, unless it can be shown that people tend to be consistently suggestible or non-suggestible in a variety of situations designed specially to measure this aspect of their personality, the very existence of this trait as a psychological mechanism must remain in doubt. Thus if it be true, as Allport (1937) suggests, that suggestibility is a generalized trait only in a very small number of people, attempts to measure it will be unsuccessful. Consequently, it will be our task to examine with special care the intercorrelations between our tests, in order to determine the generality or specificity of the trait which we are measuring.

These intercorrelations may also be useful in throwing some light on the question of group factors in suggestibility. Thus it has become customary to speak of personal or prestige suggestibility, as opposed to impersonal, non-prestige suggestibility. As tests of both personal and impersonal suggestibility were included in our battery, it will be possible to obtain definite evidence on this point.

Apart from these two questions of the unitary nature of suggestibility, and of group factors within 
the general field of suggestibility, several other psychological problems arose in the course of the experiment. These include the relation between suggestibility and intelligence, perseveration, and personal tempo; the relative suggestibility of men and women; the manner in which suggestibility is distributed ; the reliabilities of the various tests used, and various others which will be discussed later.

As the main purpose in this series of experiments was to test a theory most closely associated with the name of Janet (1924, p. 128), it seemed only fair that we should use his own definition of suggestibility. According to him, "suggestion is a particular reaction to certain perceptions; this reaction consists in the more or less complete activation of the tendency that has been evoked, without this activation being completed by collaboration with the whole personality." The tests used were chosen so as to conform with this definition; they will be described in the next section.

\section{Experimental Procedure}

The subjects.-The greatest care was exercised in the selection of the subjects, as the whole success of the experiment depended on the unequivocal presence or absence of hysterical symptoms, and on the elimination of any other points of difference between the two groups. Sixty subjects were used in all, thirty of whom were men, and thirty women. The men were, with two exceptions, soldiers referred to the hospital for psychotherapeutical treatment ; the women, with four exceptions, members of auxiliary service organizations (the A.T.S. and the W.A.A.F.) referred for the same purpose. The six exceptions were civilians referred to the hospital because of nervous disorders consequent upon bombing.

Fifteen of the men, and fifteen of the women, were diagnosed as "conversion hysterics"; in no case could there be the slightest doubt as to the presence of a severe hysteria. A number of cases of "hysterical personality" and of " anxiety hysterias" were tested, but because of the possibility of disagreement regarding the diagnosis they were not included in the experimental group. Diagnoses were made by the doctor in charge of the patient. All subjects were interviewed by the writer and their case-notes carefully scrutinized.

Fifteen men, and fifteen women, were diagnosed as being free from any major hysterical symptom. This group of subjects consisted in the main of depressives and effort syndrome cases, and included a number of patients who were not genuinely neurotic at all. Dr. A. Lewis interviewed a number of these patients who had proved particularly suggestible, and confirmed that they were not hysterical in the least.

The average ages of the resulting four groups of fifteen patients each were: Male hysterical, $27 \cdot 1$; female hysterical, $26 \cdot 5$; male non-hysterical, $26 \cdot 2$; female nonhysterical, $24 \cdot 4$. The scores of the four groups in the "Matrices " Intelligence Test are given below; it will be seen that the differences between the groups are very small.

The tests.-The tests used were all of a standard kind and a good deal of data had been accumulated with regard to the performance of children, normal adults, groups of high and low intelligence, etc., so that the results obtained in this study could be seen against a factual background.

1. Progressive weights.--This test, first described by Binet (1900), has been used extensively. Fifteen boxes, numbered 1 to 15 , are put in front of the subject in a semicircle on the table. Boxes 5 to 15 all weigh 100 grams; box 1 weighs 20 grams, box 240 grams, box 3 60 grams, and box 480 grams. The subject is told that these boxes all differ in weight (in the standard test, as described by Binet, the subject is not told anything about the weights of the boxes; the present procedure was adopted for reasons which will become apparent later on); he is required to lift them one at a time, starting with number 1 , and say whether box 2 is heavier or lighter than number 1, box 3 than box 2 , and so on. His responses are taken down in full, and after each judgment he is encouraged by the experimenter who nods approvingly and says "Yes," or "Yes, quite right," regardless of the nature of the reply. In spite of the instructions 59 out of the 60 subjects gave a number of " same " judgments.

Whipple (1921) advised scoring this test by simply counting the number of heavier judgments after the weights of the boxes had become objectively equal; this continuance of a previously correct response in spite of altered circumstances was thought to measure suggestibility. Brown (1916) and Williams (1930) in their work followed Whipple's suggestion, but Hull and Forster (1932) pointed out tha! this method of scoring left much to be desired, and suggested a different method based on the normal curve of distribution. To the present writer, it appears that two entirely different phenomena must be distinguished in the scoring. First, there is the tendency to go on calling the boxes " heavier " although they are objectively equal. This can best be measured by subtracting the number of "lighter" calls from the number of "heavier" calls on the last ten boxes.

Secondly, there is the definite suggestion that the boxes will all differ in weight from one another. Response to this suggestion can best be measured by adding the number of " heavier" and "lighter" judgments on the last ten calls. It might be argued that in the usual Binet technique no suggestion is given to the effect that the weights are different, and that therefore this particular score would be meaningless. Our answer would be that the suggestion is implicit in the procedure adopted. A number of controls to whom the ordinary Binet instructions were given were questioned as to whether they expected the weights to be the same or different; they all expected them to be different rather than the same. Thus our instructions serve simply to make the situation more definite, and eliminate the variations of "set" which are inevitable when the usual instructions are given. These two ways of scoring this test will be called " impersonal" and "personal" respectively, because the first way of scoring would seem to involve the use of impersonal suggestion, while the second method would seem to involve personal suggestion.

A second form of this test was given in order to get some idea of its reliability. This time, the first five boxes decreased in weight, and the remainder of the boxes were equal in weight to the lightest of the first five. The actual weights were 100 grams, 60 grams, 40 grams, 30 grams, 20 grams, and a series of 1020 -gram boxes. The ruliabilities, as calculated by correlating these two forms of the test, are very low. For the personal method of scoring, the reliability is 0.43 ; for the impersonal method, only 0.09 .*

2. Progressive lines.-The progressive lines test is similar in every way to the progressive weights test, except that the objects being compared are lines. Fifteen white cards, 3 by 5 inches, were used for this test. On each card a line was drawn in ink, somewhat off centre, so that judgments of length were made more difficult. The length of these lines was $\frac{1}{2}, 1,1 \frac{1}{2}, 2$ and $2 \frac{1}{2}$ inches for the remaining eleven cards.

These cards were exhibited by the experimenter at a constant rate of 1 every 5 seconds, at a distance of 4 feet from the subject's eyes. Instructions and comments were as in test (1), with the obvious modifications. A second form of the test was given in which the lines grew shorter at first; here the first line was $2 \frac{1}{2}$ inches, the second line $1 \frac{1}{2}$ inches, the next 1 inch, the next ${ }_{4}^{3}$ inch, and the remainder $\frac{1}{2}$ inch. The reliability coefficients are rather

* It should be borne in mind throughout this paper that according to Fisher's (1932) method of calculating the significance of small samples. a correlation of 0.25 is significant $(p=0.05)$, while a correlation of 0.32 is very significant $(p-0.01)$, when $n=60$. 
higher for these tests, being $\mathbf{0 . 5 7}$ for the personal method of scoring, and $\mathbf{0 . 2 4}$ for the impersonal method.

3. Body sway.-This test, first suggested by Hull (1929), has been described in detail by him, and we need only note that it consists essentially in a measured response to the suggestion of postural sway. The subject is asked to stand at ease, and to remain quite relaxed. He is then asked to close his eyes. While he stands thus, a thread is pinned on to his clothes. This thread is connected, by means of several hooks, to a weight and a pointer which run on a scale. Any movement of the subject is reflected in a movement of the pointer on the scale. The thread is attached to the clothing of the patient at a uniform height, thus making unnecessary the correction for height of the subject suggested by Hull.

While the subject stands quietly for 30 seconds the movement of the pointer is noted in order to obtain a record of the amount of sway in the abse nce of any suggestion. Then the experimenter begins to say slowly and deliberately; "Imagine you are falling forward. You are falling forward, forward. You are falling forward, forward. You are falling. You are falling forward ... ." If the subject has not fallen after $2 \frac{1}{2}$ minutes, the test is stopped and the maximum amount of sway noted.*

Scoring was in terms of maximal sway in inches; if the subject swayed 5 inches forward, his score was 5 . When the subject fell forward altogether, so that he had to be caught in order to prevent him from falling, he was given an arbitrary score of 12 if the fall came after one minute, and a score of 15 if the fall came within the minute.

In order to get a reliability coefficient, the test was repeated in each case after a few minutes, the suggestion this time being "you are falling backwards." The reliability is very satisfactory, being 0.91 .

4. Arm levitation.- Here the subject is seated on a chair and told to hold out his right arm sideways at the level of his shoulder. Then he is told to shut his eyes, and the same recording device as before is attached to his cuffs by means of the thread and needle. After his tremors and involuntary movements have been studied for 30 seconds, suggestions are made for $2 \frac{1}{2}$ minutes that his arm is feeling lighter, and is rising. Again the extent of the rise is measured on the scale.

A few minutes after the completion of this test, the same procedure is repeated with the exception that now the experimenter suggests that the arm is getting heavier, and is falling. The correlation between these two forms of the test is only $\mathbf{0 . 3 5}$. This very low value appears to be due to an important type-factor which seems to divide the suggestible subjects into two classes. Many of the older hypnotists maintained that there are two types of hypnotic subjects, called variously active and passive, or alert and lethargic ( $c f$. the works of Binet, Moll, Bernheim, Trommer, et al. for early recognition of this distinction). Recently, Young (1925), White (1937), and Davis and Kantor (1935) have revived this old distinction, and added much interesting descriptive detail. Now it would appear that in suggestibility we have a very similar difference. The active, alert subjects who are suggestible raise or lower their arms quickly and in accordance with the suggestion; the passive, lethargic subjects lower their arms when told to, but they also lower their arms when told to raise them.

This type difference would seem to account for the low reliability. We may also suggest that here we have an excellent test by means of which we can distinguish objectively between these two types of suggestibility. Further work is needed to show whether these two types are identical with the hypnotic types described by the writer quoted, and whether the results of the suggestibility test can be used to predict the type of trance into which the subject will fall.

5. Chevreul pendulum.-This test seems to have ori-

* In a few cases, subjects were found to be negatively suggestible thus two men fell over backwards when the suggestion was "Falling forward." Scoring was irrespective of the direction of the fall. ginated with Chevreul (1854). In the form used in this investigation, it consists of a small weight suspended from a thread. The experimenter holds this weight over the centre of a ruler, and tells the subject that this is a test of steadiness. The subject will be required to hold the bob still while looking from one end of the ruler to the other. The experimenter demonstrates, and as he looks from one end of the ruler to the other, and back again, the pendulum is seen to start swinging. The experimenter continues till the pendulum swings the whole length of the ruler, explaining that movements of this kind tend to occur inevitably in everybody; then hands the thread and the bob suspended from it over to the subject. The subject then looks from one end of the ruler to the other, and the amount of suggestion transmitted is measured by the amount of swing imparted to the pendulum. Scoring was in terms of maximum swing; 0 points if the swing was less than 1 inch either way, 1 point if the swing was less than 2 inches, 2 points if it was less than 4 inches, and 3 points if it was above 4 inches. This test is reported to have a retest reliability of approximately 0.90 (Saltzman, 1936).

6. As explained above, certain tests were given in addition to the suggestibility tests. The first of these was an intelligence test which is used as a routine test at the Hospital: Raven's " Matrices" test. On the basis of the scores subjects are divided into five groups, from Grade 1, the very intelligent, to Grade 5, the very dull. Full details regarding this test are given by Raven (1939, 1941). The reliability of this test is approximately $0 \cdot 90$.

7. Two tests of perseveration were given. The first consisted in having the subject write a line of S S S S S for 15 seconds, followed by a line of 222222 . Then another line of S S S S S followed by another line of 22222 . Next, the subject is asked to write for 15 seconds alternate $\mathbf{S}$ and inverted $\mathbf{S}$; this is repeated for three further periods of 15 seconds. His score is the total number of letters written in the first four periods, divided by the number written in the last four periods.

The second test is similar, triangles pointing upwards and pointing downwards being used instead of $\mathbf{S}$ and $\mathbf{S}$ reversed. The correlation between these two forms of the perseveration test is extremely low, viz. $0 \cdot 11$. Further information regarding the tests is given by Spearman (1932).

8. Personal tempo.-This concept has played a large part in German psychology (Frischeisen-Köhler, 1933; Guttman, 1931 ; Neumann, 1913 ; Braun, 1927), and also recently in American work (Reymert, 1923 ; Harrison, 1941). As a measure the total number of items written in the first 15 -second periods of the perseveration tests was used. The reliability, as calculated from the correlation between the total number of triangles and S's written, is comparatively high, viz. $\mathbf{0} 60$.

\section{Results}

Table I gives the average scores in each of the tests used for the sixty subjects, and also the standard deviations. The methods of scoring, and the reliabilities of the tests, have been discussed in the previous section.

The distribution of scores is of interest, particularly as regards the various tests of suggestibility. (In the other tests the distribution approaches the normal probability curve more or less closely.) In Figs. 1 and 2 are given histograms of the distribution of scores for the Body Sway test, the two forms of the Progressive Lines and the Progressive Weights tests, the Pendulum test, and the Arm Levitation tests. (In the Body Sway test and the Progressive Lines and Weights tests the two forms whose averages are given separately in Table I have been combined for the purpose of drawing the histogram.) 
TABLE I

Progressive weights, personal (A)

Progressive weights, impersonal (A)

Progressive lines, personal (A)

," ," , (B)

Progressive lines, impersonal (A)

, , , , (B)

Body sway, forward

,, ,, backward
$6.4 \div 2.65$ Arm levitation, up

$5.0 \div 2.84$, , down

$2.7+2.98$

$0.0 \div 2 \cdot 74$

$4 \cdot 5 \pm 2 \cdot 59$

$2 \cdot 5 \pm 2 \cdot 11$

$0 \cdot 1 \pm 2 \cdot 70$

$0 \cdot 4 \pm 1.64$

$5 \cdot 4 \div 5 \cdot 22 *$

$4 \cdot 9$ 5.66*
Perseveration, $\mathbf{S}$

, triangles

Personal tempo, S

, , , triangles

Matrices

Chevreul Pendulum
$-1 \cdot 2 \div 5 \cdot 96^{*}$

$6 \cdot 1$ 5.49*

$1 \cdot 3 \pm 0.43$

$1 \cdot 2 \pm 0.34$

$48 \pm 11 \cdot 3$

$50 \pm 13 \cdot 3$

$2 \cdot 7 \pm 1.05$

$1 \cdot 3 \pm 1 \cdot 2 *$

* The abnormal distribution of scores in these tests partly invalidates the use of the S.D.

\section{SCORES OF SIXTY SUBJECTS}

ON FOUR TESTS OF PRIMARY SUGGESTIBILITY
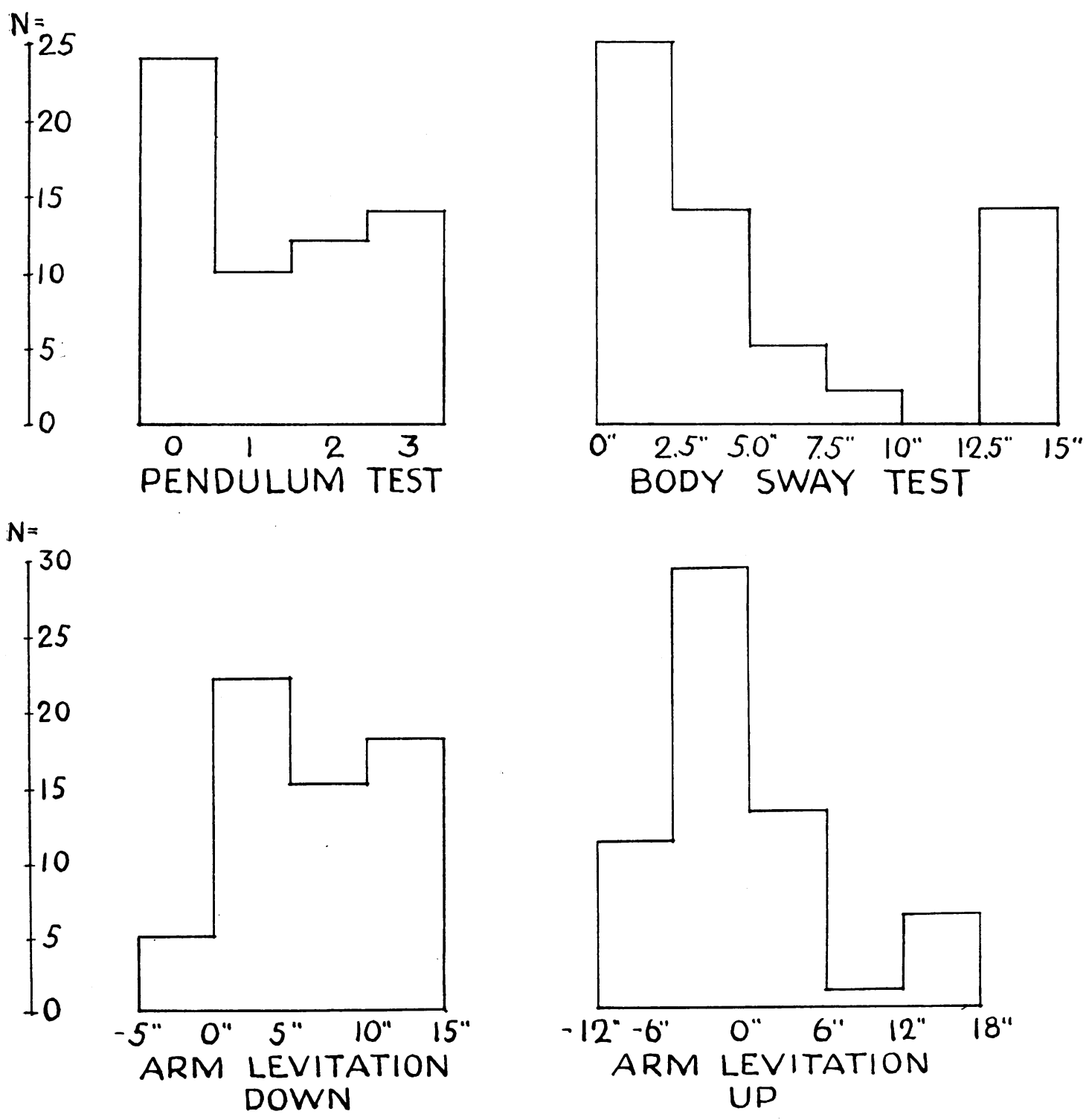

FIG. 1. 


\section{SCORES OF SIXTY SUBJECTS ON FOUR TESTS OF SECONDARY SUGGESTIBILITY}
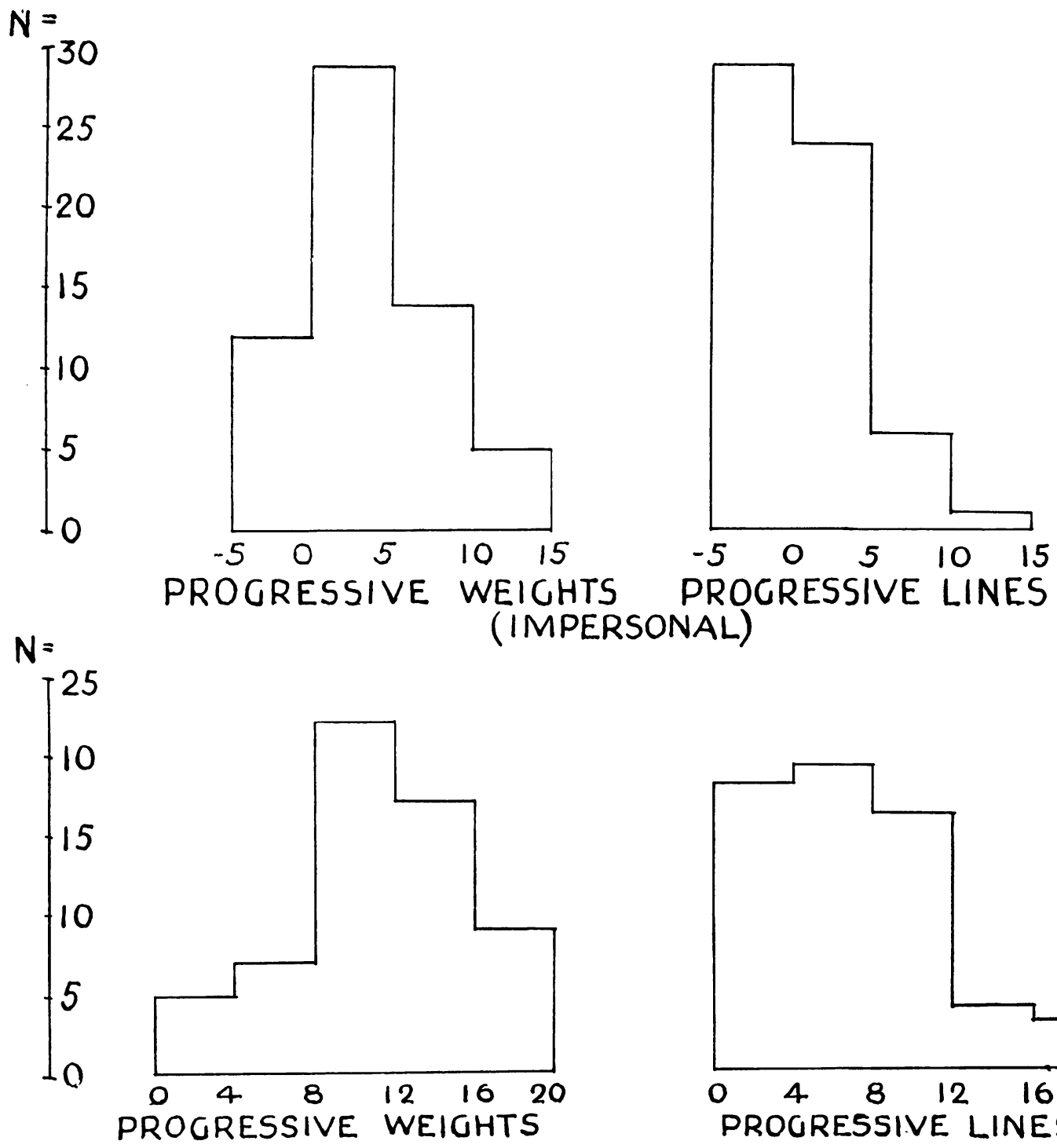

\section{(PERSONAL)}

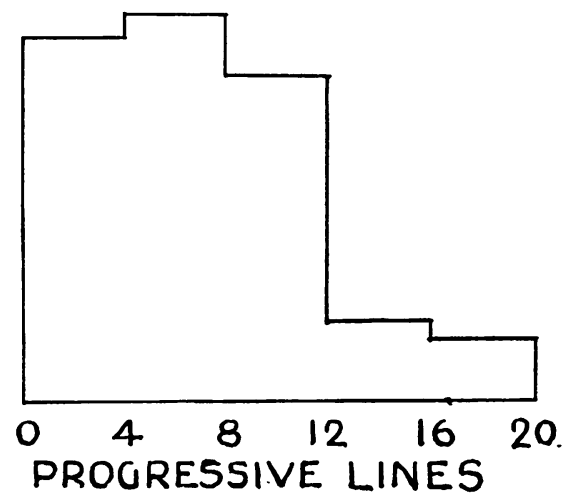

FIG. 2.

These curves confirm the suggestion made by Aveling and Hargreaves (1921), and later also confirmed by Estabrooks (1929), that " personal prestige suggestion " is characterized by a U-curved distribution while the "non-prestige suggestion" curve of distribution approaches the normal curve.* Life ( $c f$. Hull, 1933) had found an L-shaped curve of distribution when giving the Body Sway test to

* Exceptions to this rule are the progressive weights and the progressive lines test (personal forms). As we shall see later on the customary distinction between personal prestige and non-prestige tests does not accord with our experimental findings and remains to be replaced by a different distinction. For the purposes of convenience the old nomenclature is retained in this section as well as in the previous ones.
64 students; this result is probably an artifact due to the preselection of intelligence implicit in the use of university students. (The relation between intelligence and suggestibility will be discussed below.)

These curves also supply evidence on the important question of whether or not there is any negative non-prestige suggestion. Hull (1932, p. 336) considered the existence of such a phenomenon possible, but did not think that the evidence sufficed to come to any definite conclusion. It will be seen, from Fig. 2, that a fair number of our subjects are negatively suggestible when tested with the two tests used in this investigation. We may, then, consider the 
existence of negative non-prestige suggestibility as probable.

We are now in a position to compare directly our main groups of subjects with regard to their performances on these various tests. For this purpose we have combined the scores on the two forms of the Weights test (both for the Personal and Impersonal method of scoring), on the two forms of the Lines test (both methods of scoring), on the two forms of the Body Sway test, the Perseveration tests, and the Personal Tempo tests. The resulting scores, given separately for hysterics and non-hysterics, and for men and women, are shown below in Table II.

\section{TABLE II}

Test Hysterics Non-

1. Weights, personal

2. Lines, personal

$5 \cdot 8$ $5 \cdot 6$

Men Women

3. Weights, impersonal

4. Lines, impersonal $-0 \cdot 1$

5. Pendulum

$3 \cdot 0$

3.6

$$
\begin{array}{r}
5 \cdot 8 \\
3 \cdot 7
\end{array}
$$

$2 \cdot 5$

$1 \cdot 0$

$1 \cdot 0$

6. Body Sway

$1 \cdot 6$

7. Arm levitation, up $-1 \cdot 6$

8. Arm levitation,

down

$4 \cdot 5$

$-0.8$

\subsection{5}

$2 \cdot 9$

$1 \cdot 5$

$6 \cdot 5 \quad 3 \cdot 6$

$\begin{array}{lll}-0.8 & -1.5 & -0.9\end{array}$

9. Perseveration

10. Personal tempo

$7 \cdot 0$
$1 \cdot 23$

$1 \cdot 23$
$47 \cdot 3$

$5 \cdot 1$
$1 \cdot 29$
$49 \cdot 1$
$2 \cdot 5$

$6 \cdot 1$
$1 \cdot 3$

$1 \cdot 31$
$48 \cdot 5$

$2 \cdot 5$

$6 \cdot 1$

$1 \cdot 20$

$47 \cdot 5$

$2 \cdot 9$

It will be seen that for the prestige tests there are certain small differences between the groups; thus in the Pendulum and Body Sway tests the hysterics are slightly more suggestible than the non-hysterics, and the men than the women. However, when the large standard deviations of the scores are taken into account, the differences fade into insignificance; in no case is the Critical Ratio higher than 2! In other words, there is no evidence here to suggest that with respect to suggestibility there is any difference between hysterics and non-hysterics, or between men and women. The latter conclusion rather contradicts the findings of Hull (1933), working with 41 men and 28 women, and of Aveling (1921), working with 79 boys and 42 girls; who found females more suggestible. Their results, however, were of doubtful statistical significance.

Regarding the non-prestige tests, we also find no reason to assume that hysterics are more suggestible than non-hysterics; their scores are almost identical. Again we find, however, that the men are slightly more suggestible than the women, although the difference is definitely not statistically significant.
This finding is in conflict with the results reported by Messerschmidt (1933), Brown (1916), Gilbert (1894), Seashore (1895), Dressler (1894), Yung (1908), Wolfe (1898), and Hurlock (1930), who found women slightly more suggestible, while it agrees with the results reported by Otis (1924). In all these studies, however, the differences found were slight, and of doubtful significance. This question will be taken up again later on.

Next we must turn to the interrelations between the various tests of suggestibility. These are given below, in Table III. A factorial analysis shows clearly that we have to do with two entirely unrelated factors ( $c f$. Fig. 3). On the one hand, we

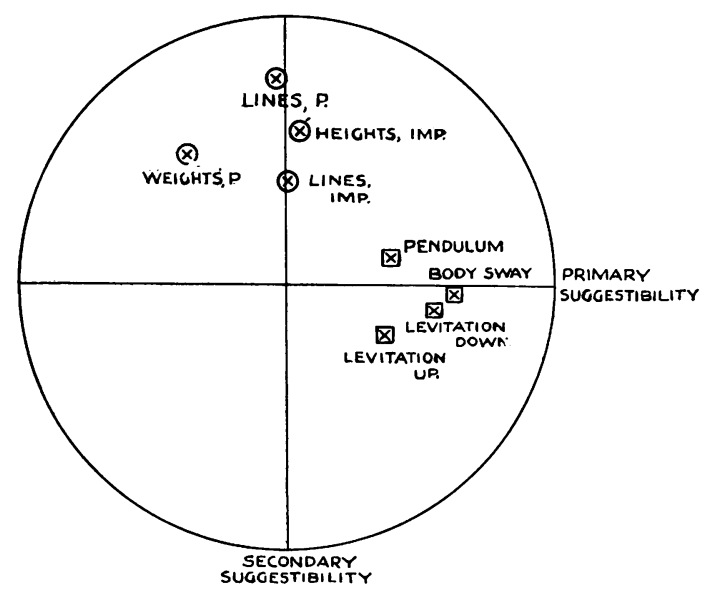

FACTORIAL PATTERN OF EIGHT TESTS OF SUGGESTIBILITY

FIG. 3.

have the Progressive Weights and Progressive Lines tests, scored both for personal and for impersonal suggestion; on the other hand we have the Pendulum, Body Sway, and the two Arm Levitation tests. An interpretation of these factors will be attempted in a later section.*

Certain other correlations are of interest. Thus the question arises as to whether intelligence is correlated with prestige suggestibility, as Hull (1933, p. 86) believes. He assembles data from eight separate investigations, carried out by Aveling and Hargreaves (1921), Barry, Mackinnon and Murray (1931), White (1930), Davis and Husband (1931), and Hull and Life (unpublished), and finds

* This particular table of correlations raises certain problems with regard to the proper method of factorial analysis to be adopted, which cannot be discussed here. An adapted form of Thurstone's (1935) method of rotation was used, the angle of rotation being $45^{\circ}$. \begin{tabular}{lcccccc} 
& & & & & TABLE III \\
& 1 & 2 & 3 & 4 & 5 \\
\hline & - & 0.610 & 0.230 & 0.121 & -0.256
\end{tabular}

2. Lines, personal

3. Weights, impersonal

4. Lines, impersonal

5. Pendulum

6. Body sway

7. Levitation, up

8. Levitation, down

$\begin{array}{ccccc}1 & 2 & 3 & 4 & 5 \\ -\quad 0.610 & 0.230 & 0.121 & -0.256 \\ & - & 0.295 & 0.194 & 0.095 \\ & & - & 0.308 & 0.144 \\ & & & - & 0.156 \\ & & & & \end{array}$

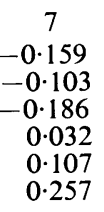

-

\begin{tabular}{ccc}
8 & Factor I & Factor II \\
-0.216 & $+\mathbf{0 . 5 0 9}$ & -0.371 \\
-0.127 & $\mathbf{+ 0 . 7 7 2}$ & -0.002 \\
0.187 & $\mathbf{+ 0 . 5 5 8}$ & $+\mathbf{0 . 0 4 8}$ \\
-0.076 & $+\mathbf{0 . 3 8 6}$ & +0.016 \\
0.174 & $+\mathbf{0 . 0 9 4}$ & $\mathbf{+ 0 . 3 8 6}$ \\
0.410 & -0.041 & $+\mathbf{0 . 6 2 3}$ \\
0.351 & -0.194 & $+\mathbf{0 . 3 7 0}$ \\
- & -0.100 & $+\mathbf{0 . 5 4 6}$ \\
\hline & +0.172 & +0.142
\end{tabular}


that among these data covering 296 subjects there are correlations ranging from +0.34 to 0.00 ; he accordingly concludes that " the ... evidence . . . is in perfect accord with the experience of hypnotists that normally intelligent individuals make the best hypnotic subjects, and that feeble-minded individuals are apt to make poor subjects " (ibid.).

The Body Sway test correlates 0.159 with intelligence, and the Pendulum test $0 \cdot 138$. These correlations are not significant statistically, but as far as they go they seem to bear out Hull's point. Careful inspection of the data, however, suggests that the product-moment correlation is not really a formula which can justifiably be used in connection with these data, as this formula demands a linear relationship between the tests correlated. When the correlation ratio $\eta$ is calculated for the Body Sway test it is found to have the comparatively high value of 0.52 . Using this value, which is definitely significant statistically, as a test of the linearity of the original data, we find $\zeta=0 \cdot 24$, which according to Blackman's test proves that the relationship is non-linear. The original data show quite clearly that in this case, as well as in the case of the pendulum and the arm levitation tests, there is a marked tendency for the highly intelligent and for the highly unintelligent to be less suggestible than the average. If, to give an illustration of this phenomenon, we divide the subjects who took part in the Body Sway test into those who were suggestible (arbitrarily defined as swaying more than $2 \cdot 5$ inches) and those who were not, we find that of those who had a 1 or 2 rating on the matrices test the same number were suggestible as not; similarly for those who had a 4 or 5 rating. For those, however, who had an average rating (Grade 3), almost four times as many were suggestible as not. Similar relations obtained in the other tests mentioned.

This curvilinear relationship between intelligence and prestige suggestibility may be responsible for the slight and non-significant differences between hysteric and non-hysteric patients, and between men and women, which are summarized in Table II. Twice as many men as women scored Grade 3 on the matrices test, and over three times as many hysterics as non-hysterics. If, then, as we have shown, there is a connection between medium intelligence and high suggestibility, we would expect men and hysterics to score slightly higher than women and non-hysterics, which is precisely what we found. This non-linear relationship may also explain some of the rather conflicting results obtained by earlier workers, summarized above.

As regards the non-prestige tests, there are few significant correlations with intelligence in our data; the Weights test and the Lines test, both "personal", form, correlate negatively with intelligence $(-0 \cdot 126$ and -0.278 respectively). Scored "impersonally", the correlations are respectively $-0 \cdot 299$ and $+0 \cdot 112$. These almost uniformly negative correlations are well in line with the results reported by Simmons (1940), and seem to justify the use made of tests of this kind in the testing of intelligence by Binet. It should be noted that none of these tests shows a curvilinear relationship with intelligence when the scatter-diagrams are analysed.

There are certain further correlations which have at least a suggestive value. Both the Arm-Levitation tests are correlated negatively with perseveration ( -0.165 and -0.261 ; the latter value is significant). The perseverator, it would appear, is more difficult to move in the desired direction than the nonperseverator. This analysis, however, is not borne out by the correlation of the Perseveration test with the Body Sway test, which is almost zero $(+0.039)$, or with the Pendulum test, which is $+0 \cdot 120$.

Personal Tempo correlates negatively with the Pendulum test $(-0 \cdot 182)$, the Body Sway test $(-0.234)$, and the Arm Levitation test, where the arm is raised $(-0.215)$; the correlation with the " arm down" Levitation test is positive, however $(+115)$. Correlations with the impersonal Weights and Lines tests are also negative $(-0.262$ and $-0 \cdot 114)$. It would appear that the person who is quick is less susceptible to both kinds of suggestion.

Personal Tempo is not related to perseveration, the correlation being quite insignificant $(-0.056)$. The correlation of Personal Tempo with intelligence is almost significant $(-0 \cdot 232)$, but difficult to interpret. Perseveration is not significantly related to intelligence $(0 \cdot 108)$.

Apart from the information contained in the various scores and correlations given above, a good deal of information was obtained which does not admit of quantification, but which may be of importance in determining the nature of suggestibility. This information is derived from interviews, study of the case papers, and observation of the patients while they were being tested. It became obvious very soon that in the Personal Prestige tests, i.e. the Body sway test, the two Arm Levitation tests, and to a smaller extent in the Pendulum test also, we were dealing with two separate factors, viz. aptitude and attitude. These factors appeared most obviously in the Body Sway test, and we shall therefore attempt to elucidate our meaning by describing certain typical reactions to that test.

As regards aptitude, there was quite clearly a definite graduation in the amount of emotional response to the whole situation, ranging from complete indifference to almost somnabulistic trance. As regards attitude, there was a similar graduation from very favourable through neutral to very unfavourable. (One woman opened her eyes after suggestion had begun and said : "Oh, doctor, I do so much want to be suggestible!" She proved extremely unsuggestible. A man shook his head all the time that suggestion was proceeding, and said " no!" quite audibly whenever it was suggested to him that he was falling. He proved very suggestible nevertheless.)

We are justified in making the differentiation between aptitude and attitude for the following reason. It is easy to see whether the patient is helpful, tries to co-operate, and generally has a favourable attitude towards the experimental situa- 
tion, and the experimenter, or whether he is difficult, indifferent, or actively hostile towards situation and experimenter, and generally tries to counteract every suggestion. If this attitude determined the outcome of the experiment, clearly we would not have to go any further in order to look for an explanation of the phenomena encountered. But the correlation between attitude and suggestibility is far from perfect; two instances of an inverse relationship are quoted above.

Consequently we have to assume another factor, which we have called aptitude. When this aptitude is absent, even the most favourable attitude will not make the patient concerned suggestible; compare the case of the woman described in the penultimate paragraph. When the aptitude is present, however, certain reactions are bound to appear. If aptitude is joined to positive attitude, we find the ideal suggestible subject, who reacts almost at once to everything that is suggested to him. If aptitude is joined to negative attitude, however, very interesting manifestations become apparent. The patient clenches his fists, begins to tremble violently as he fights against the power of the suggestion; the women often break out in tears and may be unable to finish the experiment. These emotional reverberations are very powerful; they seem consequent in every case upon the conflict between aptitude and negative attitude. Sometimes, as in the case mentioned above, the patient proves very suggestible in spite of his negative attitude; his conscious opposition is powerless against the force of the suggestion.

It might be thought that perhaps here we have the reason why our results did not show any difference between hysterics and non-hysterics; the hysterics, it might be said, have greater aptitude but perhaps a more negative attitude. This suggestion, however, is not borne out by the facts; both aptitude and attitude seem to be evenly distributed among hysterics and non-hysterics. (The judgment of attitude is based on direct observation, questioning of the patients, and perusal of the case notes.)

The introspections of the patients are very revealing. After each test the patients were encouraged to talk freely about the way they reacted, how they " felt about it," what it "felt like," and so on. Those who showed themselves suggestible felt as if they were being pulled forward by somebody, or as if their arms (in the Levitation test) were being pushed down or up, as the case might be. One patient said the words of the suggestion gave him " electric shocks." They were often unconscious of the extent of their reaction; some did not know, for instance, that their arm had moved through an angle of almost $90^{\circ}$, and looked for it at the place where it had been when the levitation experiment started!

One reaction is of interest, as it may give some comfort to adherents of the Freudian school (e.g. S. Ferenczi): One girl, when asked what it had felt like, doing the Body Sway test, answered: "Like falling in love!" She was rather a stupid girl, and the superficially plausible explanation that she was trying to flirt does not seem very probable.

\section{Discussion}

The results reported in Table III show very clearly that there are two quite independent types of suggestibility. Due largely to the work of Aveling and Hargreaves (1921) and of Hull (1933), such a distribution has been recognized for a long time, and has usually been related to the presence or absence of personal or prestige suggestion. Our results do not bear out this theory. The Progressive Lines and Weight tests, personal form, correlate significantly with the Progressive Lines and Weights, impersonal form, although in the personal form we are dealing with prestige suggestion; they do not correlate with the other personal prestige tests, i.e. Body Sway, Arm Levitation, and Pendulum.

Consequently it will be necessary to renounce the view that the difference between the two groups of tests is due to the presence or absence of personal prestige suggestion. In order to avoid implying a theory by the names given to the two types of suggestibility, we shall call the suggestibility measured by the Body Sway test, the Arm Levitation tests, and the Pendulum test primary suggestibility, and the suggestibility measured by the Progressive Weights and the Progressive Lines tests, both in their personal and impersonal forms, secondary suggestibility.

We may perhaps set out briefly the four main reasons for regarding these two types of suggestibility as entirely independent and separate. In the first instance, as we have seen, there is no correlation between tests of primary and of secondary suggestibility. Secondly, as Aveling and Hargreaves (1921) and Estabrooks (1929) have shown, and as we have been able to confirm, primary suggestibility is distributed in the form of a U-curve, while secondary suggestibility follows the more normal probability curve. Thirdly, as we have shown, primary suggestibility is related in a curvilinear manner to intelligence, while secondary suggestibility is related to intelligence in a linear manner. And lastly, as Hull (1932) has shown, practice increases primary suggestibility and decreases secondary suggestibility.*

There is strong evidence that primary suggestibility is related to hypnotizability (Beck, 1936; Saltzman, 1936; Dorcus, 1937; Jenness and Wible, 1937; Krueger, 1931; White, 1937; see, however, Williams, 1930; Wells, 1931), and consequently to dissociation (White and Shevach, 1942). We might, therefore, speak about dissociative suggestibility as opposed to non-dissociative suggestibility. However, there are certain difficulties in this theory. Dissociation is usually regarded as a neurotic symptom; it has been shown, however, that neurotics and normals do not differ significantly with respect to primary suggestibility (Bartlett, 1936; Messer, Hinckley and Mosier, 1938). Will dissociation go the same way

* A further point might possibly be that tests of primary suggestibility show high reliability, while tests of secondary suggestibility show low reliability. 
as suggestibility, which was first regarded as purely neurotic (Charcot, Janet), then as normal, but hypertrophied in neurosis (Bernheim et al.), and finally appear to be entirely normal and quite unrelated to neurosis? This question cannot be answered here, for experimental evidence is lacking. Until such evidence is provided, we may well retain such a neutral term as " primary suggestibility."

Secondary suggestion does not seem to involve any dissociation at all. The reason for this difference may easily lie in a factor stressed by the writer in connection with the improvement of mental and physical functions in the hypnotic state (Eysenck, 1939). It was shown there that the easiest, least complex performances, such as tapping, improved most under hypnosis, while the more complex performances improved little or not at all. The reason seemed to be that simple tasks involve only a small part of the cerebrum, which becomes easily dissociated, while complex tasks require the collaboration of large parts and tracts of the brain, thus making dissociation particularly difficult. Similarly here, primary suggestibility seems to be concerned mainly with simple, straightforward tasks, requiring essentially the construction of one ideo-motor pathway, while secondary suggestion requires complex processes of judgment, thus involving the whole cortex. Under these conditions, dissociation is impossible.

When the scores of our patients on the various tests are compared with scores made by non-neurotic subjects on similar tests as reported in the literature, it is found that there is very little difference. This result is in good agreement with the findings of Bartlett (1936), who found no difference between neurotics and normals in the Body Sway test. The reason for the general over-estimation of the suggestibility of neurotics in general, and hysterics in particular, seems to lie in the fact that judgments have up to now been based mainly on clinical impressions, i.e. almost exclusively on abnormal cases. Finding these abnormal cases very suggestible, and lacking a normal control group with which to compare them, quite naturally psychiatrists came to the conclusion that neurotics were particularly suggestible. A study of a normal group would soon have shown that suggestible people are found just as frequently among normal groups as among neurotics. The point is amusingly illustrated in a recent paper by Vega (1941), who found pregnant women particularly suggestible; quite clearly no such conclusion is warranted in the absence of a control group.

It is important to emphasize this point; our study found hysterics and non-hysterics equal in suggestibility not because the hysterics were nonsuggestible; they were very suggestible, but so were the non-hysterics. This eliminates one possible objection to our conclusion. Mapother and Lewis (1938, p. 1871) point out that " the much-stressed suggestibility of hysterics is a notable aspect of their especial responsiveness to a person with whom they develop an emotional relationship, often un- recognized by themselves as such.' It might be said that the experimental situation failed to produce the necessary "emotional relationship." Such a criticism, however, would seem to be unfounded in view of the fact that in the particular situation of the experiment hysterics did prove to be very suggestible. It was only the surprising suggestibility of the nonhysteric group which forced us to deny the greater suggestibility of hysterics.

\section{Summary}

The evidence presented in this paper, based on the scores made by 15 hysteric men, 15 hysteric women, 15 non-hysteric men, and 15 non-hysteric women on eight tests of suggestibility, a test of intelligence, two tests of personal tempo, and two tests of perseveration, on the intercorrelations of these tests, on clinical histories of the 60 cases, on personal interviews, and on the introspections of the patients, seems to lead to the following conclusions :

1. In none of the tests of suggestibility used was there any significant difference between the hysterical and the non-hysterical group.

2. In none of the tests of suggestibility used was there any significant difference between men and women.

3. There was no significant difference between hysterics and non-hysterics in the tests of perseveration.

4. There was no significant difference between hysterics and non-hysterics in the tests of personal tempo.

5. The tests of suggestibility used fell into two sharply differentiated groups, called " primary suggestibility" and "secondary suggestibility", respectively.

6. Primary suggestibility is distributed in the experimental population in the shape of a U-curve.

7. Secondary suggestibility is distributed in the experimental population in the shape of a normal curve.

8. Primary suggestibility is correlated significantly with intelligence, the correlation being significantly 3 non-linear. (Subjects of average intelligence proved \& to be the most suggestible group ; neither the highly 3 intelligent nor the dull were particularly suggestible.) 을

9. Secondary suggestibility is correlated significantly with intelligence, the correlation being linear. The more intelligent the subject the less suggestible will he be on the average.

10. Evidence was found for the existence of $N$ negative primary and of negative secondary sug- N gestibility.

11. Two factors were found to be active in primary suggestibility, viz. aptitude and attitude.

12. Primary suggestibility was shown to involve an important type factor, dividing those who were $\square$ suggestible into an active, alert group, and a passive, $\bar{O}$ lethargic group. This differentiation was found to be well in line with a similar distinction often made $\frac{\overrightarrow{\mathbb{D}}}{\mathbb{Q}}$ in the field of hypnosis.

13. Tests of primary suggestibility show high reliability. 
14. Tests of secondary suggestibility show low reliability.

15. The results suggest that personal tempo is related negatively to both primary and secondary suggestibility.

16. Perseveration does not show any clearly defined relation to either primary or secondary suggestibility.

The writer is indebted to the Rockefeller Foundation for a grant which enabled him to carry out this research. He also takes pleasure in acknowledging his indebtedness to Dr. W. S. Maclay, Superintendent of Mill Hill Emergency Hospital, for the opportunity to carry out the research; to Dr. A. Lewis, Clinical Director, for invaluable help and advice; and to the medical staff of the hospital generally for their generous co-operation.

\section{REFERENCES}

Allport, G. W. (1937). Personality, Constable, London. Aveling, F., and Hargreaves, H. L. (1921-22). Brit. J. Psychol., 12, 53.

Babinski, J. F., and Froment, J., (1918). Hysteria or Pithiatism, Univ. London Press.

Barry, H., Mackinnon, D. W., and Murray, H. A. (1931). Human Biology, 3, 1.

Bartlett, M. R. (1935). Arch. Psychol., No. 182.

(1936). J. gen. Psychol., 15, 191.

Beck, L. F. (1936). Psychol. Bull., 33, 747.

Bernheim, H. (1887). De la Suggestion, et de ses applications à la thérapeutique, Paris.

Binet, A. (1900). La Suggestibilité, Schleicher, Paris.

Braun, F. (1927). Arch. ges. Psychol., 60, 317.

Brown, W. (1916). Univ. Calif. Publ. Psychol., 2, 291.

Cameron, H. C. (1929). The Nervous Chiid, 4th Edition, Oxford Univ. Press.

Cattell, R. B. (1936). A Guide to Mental Testing, London Univ. Press.

Chevreul, M-E. (1854). De la Baguette Divinatoire, etc., Mallet-Bachelier, Paris.

Davis, L. W., and Husband, R. W. (1931). J. abnorm. (soc.) Psychol., 26, 175.

Davis, R. C., and Kantor, J. R. (1935). J.gen. Psychol., 13,62 .

Dorcus, R. M. (1937). Amer. J. Psychol., 49, 82

Dressler, F. B. (1894). Ibid., 6, 313.

Estabrooks, G. H. (1929). Ped. Sem. and J. Genet. Psychol., 36, 120.

Ewen, J. H. (1934). A Handbook of Psychiatry, Wood, Baltimore.

Eysenck, H. J. (1939). Brit. J. med. Psychol., 18, 304.

Fisher, R. A. (1932). Statistical Methods for Research Workers, 4th Edition, Oliver and Boyd, London.

Fisher, V. E. (1937). An Introduction to Abnormal Psychology, MacMillan, New York.

Frischeisen-Köhler, I. (1933). Das persönliche Tempo, Thieme, Berlin.

Gilbert, J. A. (1894). Stud. Yale psycholog. Lab., 2, 40.

Guttmann, A. (1931). Z. angew. Psychol., 40, 65.

Harrison, R. (1941). J. gen. Psychol., 24, 343.

Hirschlaff, L. (1919). Hypnotismus und Suggestivtherapie. Barth, Leipzig.

Hull, C. L. (1929). J. abnorm. (soc.) Psychol., 24, 153.
Hull (1933). Hypnosis and Suggestibility, AppletonCentury, New York.

_- and Forster, M.C. (1932). J. exp. Psychol., 15, 700 .

Hurlock, E. B. (1930). Ped. Sem. and J. Genet. Psychol., 37, 59 .

Jacoby, G. W. (1912). Suggestion and Psychotherapy, Scribner, New York.

Janet, P. (1907). Major Symptoms of Hysteria, Macmillan, New York.

- (1924). Principles of Psychotherapy, Alien and Unwin, London.

Jenness, A., and Wible, C. L. (1937). J. gen. Psychol., $16,197$.

Krueger, R. G. (1931). J. abnorm. (soc.) Pscyhol., 26, 131.

Mapother, E., and Lewis, A. (1938). Psychological Medicine, in : Price, Textbook of the Practice of Medicine, Oxford Univ. Press.

McDougall, W. (1911). Article on "Suggestion" in Encyclop. Britt.

Messer, A. L., Hinckley, E. D., and Mosier, C. I. (1938). J. gen. Psychol., 19, 391.

Messerschmidt, R. (1933). Ped. Sem. and J. Genet. Psychol., 43, 405.

Morgan, J. B. (1936). The Psychology of Abnormal People, Longmans, New York.

Neumann, E. (1913). Vorlesungen zur Einfiihrung in die Experimentelle Pädagogik., Engelmann, Berlin.

Noyes, A. P. (1939). Modern Clinical Psychiatry, 2nd Edition, Saunders.

Otis, M. (1924). Arch. Psychol., Nos. 64-70, 5.

Raven, J. C. (1939). Brit. J. med. Psychol., 18, 16. (1941). Ibid., 19, 137.

Reymert, M. L. (1923). Scand. sci. Rev., 2, 177.

Rosanoff, A. (1920). Manual of Psychiatry, Wiley, London.

Saltzman, B. (1936). Univ. Oregon psychol. Bull., 33, 622

Satow, L. (1923). Hypnotism and Suggestion, London.

Seashore, C. E. (1895). Stud. Yale psycholog. Lab., 3, 1.

Shaffer, L. F. (1936). The Psychology of Adjustment, Houghton Mifflin, New York.

Simmons, R. M. (1940). A Study of a Group of Children of Exceptionally High Intelligence Quotient in Situations Partaking of the Nature of Suggestion, Teachers Coll. Col. Univ. Contrib. Educ., No. 788.

Spearman, C. E. (1932). The Abilities of Man, Macmillan, London.

Stephenson, W. (1934). Brit. J. med. Psychol., 14, 105.

Thurstone, L. L. (1935). The Vectors of Mind, Chicago Univ. Press.

Travis, L. E. (1924). J. abnorm. (soc.) Psychol., 19, 283.

Travis, R. C. (1926). Psychol. Monogr., 30, No. 168, 18.

Tuckey, C. L. (1921). Treatment by Hypnosis and Suggestion, Baillère, Tindall and Co., London.

Vega, A. M. (1941). Bol. Col. méd. Camaguey, 4, 142.

Wells, W. R. (1931). J. abnorm.(soc.) Psychol., 25, 436.

Whipple, G. M. (1921). Manual of Mental and Physical Tests, Warwick and York, Baltimore.

White, M. M. (1930). J. abnorm. (soc.) Psychol., 25, 293.

White, R. W. (1937), J. Psychol., 3. 265.

White, R. W., and Shevach, B. J. (1942). J. abnorm. (soc.) Psychol., 37, 309.

Williams, G. (1930). Arch. Psychol., N.Y., No. 122.

Wolfe, H. K. (1898). Psychol. Rev., 5, 25.

Young, P. C. (1925). Amer. J. Psychol., 36, 214.

Yung, E. (1908). Arch. Psychol., Genève, 8, 263. 